\title{
Management of Biosphere Reserves in Vietnam: Status and Challenges
}

\author{
Nguyen Van Hieu ${ }^{1, *}$, Dang Thi Thanh Thuy ${ }^{1}$, Nguyen Hoang Nam ${ }^{2}$ \\ ${ }^{I}$ Capacity Development Center for Environment and Natural Resources (CEN), \\ 97 Van Cao, Ba Dinh, Hanoi, Vietnam \\ ${ }^{2}$ Institute of Strategy and Policy on Natural Resources and Environment (ISPONRE), \\ 479 Hoang Quoc Viet, Cau Giay, Hanoi, Vietnam
}

Received 08 July 2020

Revised 22 December 2020; Accepted 14 January 2021

\begin{abstract}
Vietnam has the second largest number of biosphere reserves (BRs) in Southeast Asia with 9 BRs, covering over 4.3 million hectares. Based on the specific conditions of each locality, some BRs have implemented a number of activities for sustainable management. However, there have been certain challenges to the effective management of BRs in Vietnam. This paper analyzes these challenges, including management policy aspect, organizational management, organizational management practices, and resources for management. The analysis results show that the term of BR has not yet been institutionalized in the national legal system as a unified management entity. In addition, the management structure and plan of the biosphere reserve is not consistent and not fully delineated at both national and local levels. The development and implementation of plans, coordination, cooperation and information sharing among key stakeholders at the BRs are inadequate. Moreover, there is difficulty in achieving the best results in implementing these activities and resources for management are still insufficient, especially human and financial resources.
\end{abstract}

Keywords: Biosphere reserves, management, status and challenges, resources for management.

\footnotetext{
${ }^{*}$ Corresponding author.

Email address: hieunguyen@ cen.org.vn
}

https://doi.org/10.25073/2588-1116/vnupam.4253 


\title{
Quản lý các khu dự trữ sinh quyển ở Việt Nam: Thực trạng và thách thức
}

\author{
Nguyễn Văn Hiếu ${ }^{1, *}$, Đặng Thị Thanh Thủy ${ }^{1}$, Nguyễn Hoàng Nam² \\ ${ }^{1}$ Trung tâm Phát triển nguồn nhân lực Tài nguyên và Môi trường (CEN), \\ 32, Ngõ 97 Văn Cao, Ba Đình, Hà Nội, Việt Nam \\ ${ }^{2}$ Viện Chiến luợc Chính sách Tài nguyên và Môi truờng (ISPONRE), \\ 479 Hoàng Quốc Việt, Cầu Giấy, Hà Nội, Việt Nam \\ Nhận ngày 08 tháng 7 năm 2020 \\ Chỉnh sửa ngày 22 tháng 12 năm 2020; Chấp nhận đăng ngày 14 tháng 01 năm 2021
}

\begin{abstract}
Tóm tắt: Việt Nam có số lượng khu dự trữ sinh quyển (KDTSQ) đứng thứ hai ở khu vực Đông Nam Á với 9 khu, diện tích trên 4,3 triệu ha. Dựa vào điều kiện cụ thể của từng địa phương, nhiều KDTSQ đã triển khai một số hoạt động để quản lý theo hướng bền vững. Tuy nhiên, hiện vẫn tồn tại một số các thách thức trong quản lý cần phải được giải quyết để để đảm bảo hiệu quả quản lý của các KDTSQ tại Việt Nam. Bài viết phân tích các thách thức này, bao gồm các thách thức về chính sách quản lý, tổ chức bộ máy quản lý, tổ chức thực hiện hoạt động quản lý và nguồn lực cho quản lý. Kết quả cho thấy, hiện tại, KDTSQ vẫn chưa được thể chế hóa trong hệ thống luật pháp quốc gia như một chủ thể quản lý thống nhất. Cơ cấu quản lý, kế hoạch quản lý KDTSQ không thống nhất và không được phân định đầy đủ ở cả cấp quốc gia và cấp địa phương. Việc xây dựng và thực hiện các kế hoạch, điều phối, hợp tác và chia sẻ thông tin giữa các bên liên quan tại các KDTSQ còn chưa đầy đủ và việc thực hiện còn gặp nhiều khó khăn để đạt đến hiệu quả cao nhất. Ngoài ra, nguồn lực cho quản lý vẫn còn một số hạn chế, đặc biệt là nhân lực và tài chính.
\end{abstract}

Từ khóa: Khu dự trữ sinh quyển, quản lý, thực trạng và thách thức, nguồn lực cho quản lý.

\section{Mở đầu}

Khu dự trữ sinh quyển (KDTSQ) là các khu vực có hệ sinh thái trên cạn hoặc ven biển có vai trò quan trọng trong việc bảo tồn và cung cấp các giá trị nhân văn, kỹ năng và khoa học, hỗ trợ cho sự phát triển bền vững [1]. Các KDTSQ do chính phủ các nước đệ trình và được công nhận bởi Chương trình Con người và Sinh quyển của Tổ chức Giáo dục, Khoa học và Văn hóa Liên Hiệp
Quốc (UNESCO MAB) khi đáp ứng 7 tiêu chí theo quy định của Điều 4, Khung Pháp lý của Mạng lưới toàn cầu các KDTSQ thế giới được thông qua tại Đại hội đồng UNESCO năm 1995 [2]. Các KDTSQ được xem là mô hình góp phần thực hiện các Mục tiêu Phát triển Bền vững (SDGs) và các Thỏa thuận Đa phương về Môi trường (MEA) [3]. Hiện tại, trên toàn thế giới có 701 KDTSQ thuộc 124 quốc gia [4]. Cấu trúc của một KDTSQ được thể hiện tại Hình 1.

\footnotetext{
*Tác giả liên hệ.

Địa chi email: hieunguyen@ cen.org.vn

https://doi.org/10.25073/2588-1116/vnupam.4253
} 


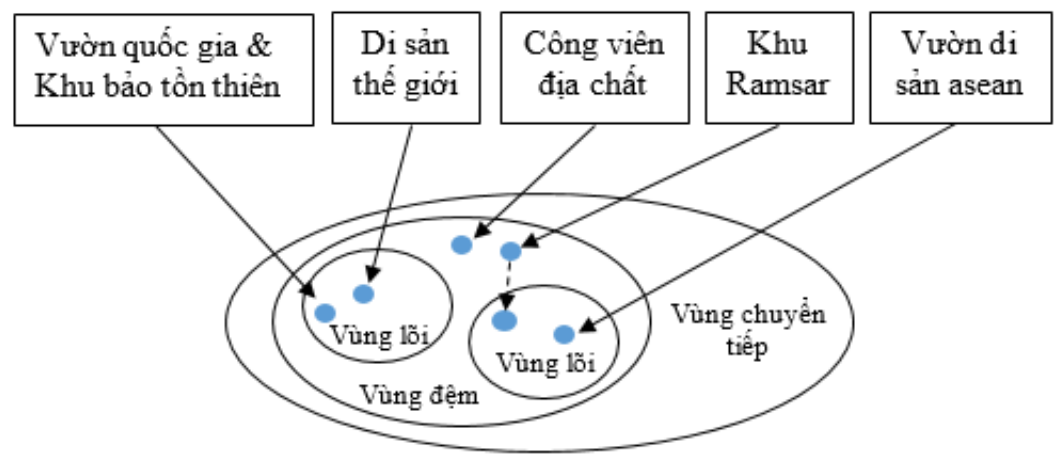

Hình 1. Cấu trúc một KDTSQ.

Nguồn: Tri et al., (2014) [5].

Các KDTSQ có 3 chức năng chính, gồm: bảo tồn (cảnh quan, hệ sinh thái, loài và đa dạng gen), phát triển (kinh tế, văn hóa), hỗ trợ (nghiên cứu, giáo dục và đào tạo) $[2,5,6]$. Việc quản lý các KDTSQ được dựa trên nguyên tắc khung do UNESCO MAB đề ra, bao gồm: 1) có cơ chế để quản lý các hoạt động khai thác và sử dụng của con người tại vùng đệm/hoặc các vùng; 2) có chính sách/kế hoạch quản lý KDTSQ; 3) có cơ chế để thực hiện các chính sách/kế hoạch quản lý KDTSQ; 4) có các chương trình nghiên cứu, giám sát, giáo dục và đào tạo [2]. Như vậy, có thể hiểu việc quản lý KDTSQ là sự kết hợp chặt chẽ giữa khai thác và bảo tồn để duy trì ba chức năng của KDTSQ [7]. Cách tiếp cận này mở rộng so với cách tiếp cận quản lý vùng lõi (vườn quốc gia, khu bảo tồn thiên nhiên,...) được thiết lập với mục đích chính là bảo tồn [8].

Cho đến hiện nay, Việt Nam có 9 KDTSQ được (UNESCO) công nhận. Trong khu vực Đông Nam Á, Việt Nam đứng thứ 2 về số lượng KDTSQ (sau Indonesia với $16 \mathrm{khu}$ ) [9]. Các KDTSQ của Việt Nam có các hệ sinh thái (HST) hết sức đa dạng (HST biển đảo, rừng ngập mặn ven biển và biển, rừng nhiệt đới gió mùa, rừng nhiệt đới, rừng trên đất liền và đất ngập nước nội địa). 9 KDTSQ đã được công nhận bao gồm: KDTSQ rừng ngập mặn Cần Giờ (công nhận năm 2000), KDTSQ quần đảo Cát Bà (công nhận năm 2004), KDTSQ Châu thổ sông Hồng (công nhận năm 2004), KDTSQ ven biển và biển đảo Kiên Giang (công nhận năm 2006), KDTSQ miền Tây Nghệ An (công nhận năm 2007), KDTSQ Mũi Cà Mau (công nhận năm 2009), KDTSQ Cù Lao Chàm - Hội An (công nhận năm 2009), KDTSQ Đồng Nai (công nhận năm 2011nâng cấp và mở rộng từ KDTSQ Cát Tiên được công nhận năm 2001), KDTSQ Lang Biang (công nhận năm 2015).

Hiện nay, 9 KDTSQ của Việt Nam có tổng diện tích hơn 4,3 triệu ha, chiếm khoảng 13,12\% diện tích tự nhiên của cả nước [10]. Diện tích vùng lõi ( 9 vườn quốc gia, 4 khu bảo tồn thiên nhiên và 2 khu bảo vệ cảnh quan), vùng đệm và vùng chuyển tiếp của các KDTSQ lần lượt chiếm khoảng $10,8 \% ; 31,1 \%$; và $58,1 \%$ tổng diện tích của các KDTSQ. Trong đó, có 4 KDTSQ (Cần Giờ, Cát Bà, Châu thổ sông Hồng và Cù Lao Chàm - Hội An) là tương đối phù hợp theo tiêu chí diện tích của Cộng hòa Liên bang Đức, còn 5 KDTSQ còn lại đều có diện tích lớn hơn diện tích tối đa từ khoảng 2 lần (Lang Biang, Mũi Cà Mau), đến hơn 6 lần (Đồng Nai) và khoảng 8 lần (Kiên Giang, Tây Nghệ An) diện tích tối đa của một KDTSQ [11]. Trong khi đó, có $2 \mathrm{KDTSQ}$ là nhỏ hơn tiêu chí diện tích của Nam Phi (Cát Bà, Cù Lao Chàm - Hội An) [12]. Đặc điểm về diện tích và vị trí của các KDTSQ tại Việt Nam được thể hiện tại Hình 2. 


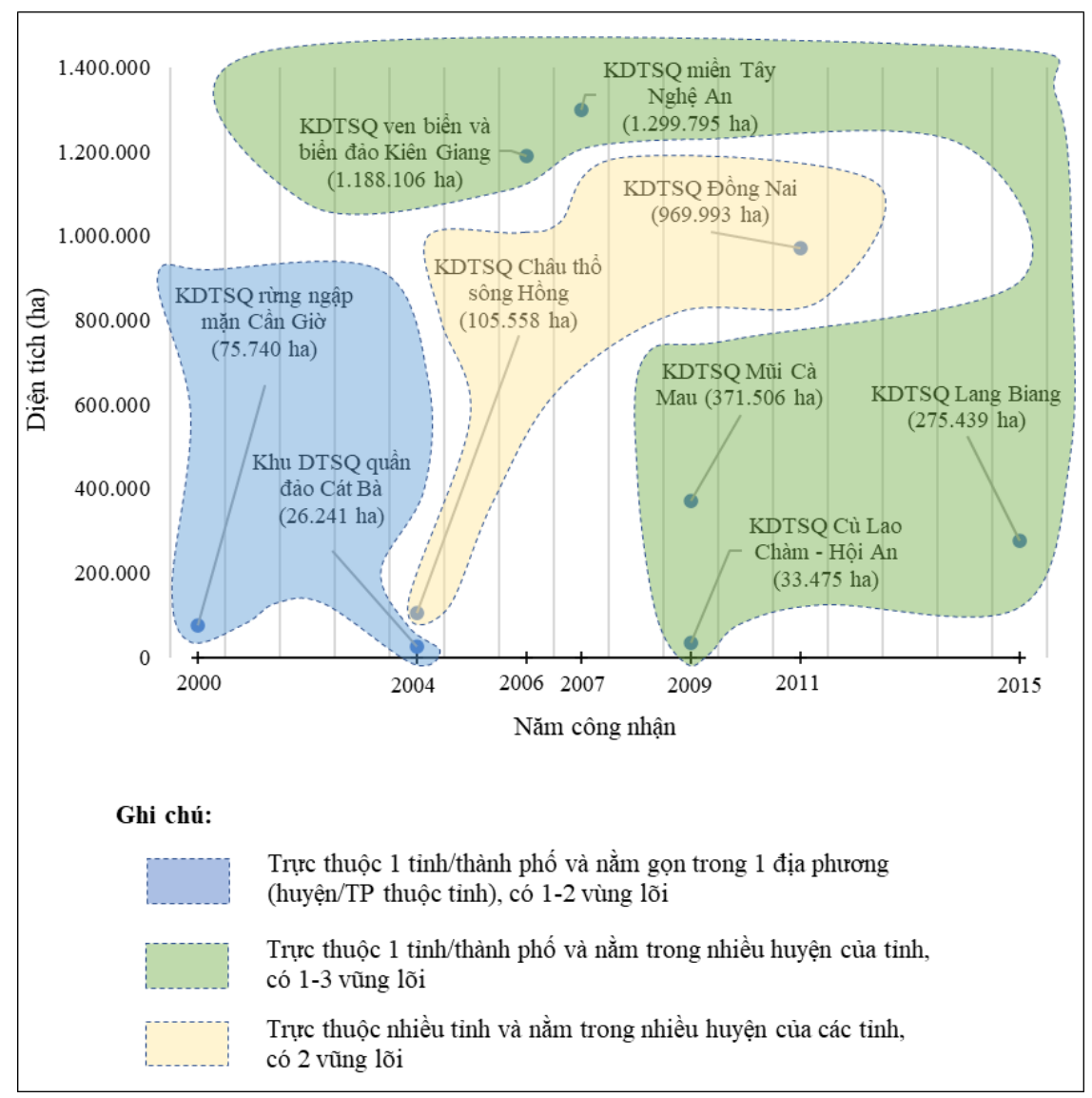

Hình 2. Đặc điểm về diện tích và vị trí các KDTSQ tại Việt Nam. Nguồn: Tổng hợp của tác giả.

Như vậy, sau 20 năm Việt Nam chính thức là thành viên Mạng lưới các KDTSQ thế giới, cho đến nay, số lượng và diện tích các KDTSQ của Việt Nam đã gia tăng một cách mạnh mẽ. Nghiên cứu này được thực hiện với mục đích đánh giá hiện trạng cũng như làm nổi bật những thách thức trong việc quản lý các KDTSQ tại Việt Nam.

\section{Phương pháp nghiên cứu}

Nghiên cứu sử dụng phương pháp nghiên cứu tại bàn và tham vấn chuyên gia để tìm hiểu hiện trạng, phát hiện những thách thức trong quá trình quản lý các KDTSQ tại Việt Nam. Các tài liệu liên quan về hệ thống thể chế luật pháp, các chính sách, quy định của các cơ quan quốc tế
(UNESCO MAB) và Việt Nam, các báo cáo của các KDTSQ và các nghiên cứu liên quan khác được thu thập, phân tích và đánh giá. Khung tiếp cận đánh giá được thể hiện tại Hình 3.

Phương pháp tham vấn chuyên gia thực hiện trong nghiên cứu này nhằm xác nhận các thông tin, kiểm tra chéo, cập nhật và đánh giá các thông tin tổng hợp được từ tài liệu thứ cấp và các nghiên cứu đã có. Theo đó 8 chuyên gia đang công tác tại Bộ Nông nghiệp và Phát triển Nông thôn (NN\&PTNT), KDTSQ (Cát Bà và Châu thổ sông Hồng) và các tổ chức phi chính phủ đang triển khai các hoạt động dự án tại các KDTSQ đã được lựa chọn để phỏng vấn sâu. Các nội dung tham vấn gồm có: chính sách và các quy định về quản lý KDTSQ; đánh giá thuận lợi, khó khăn và thách thức trong quá trình quản lý các KDTSQ. 


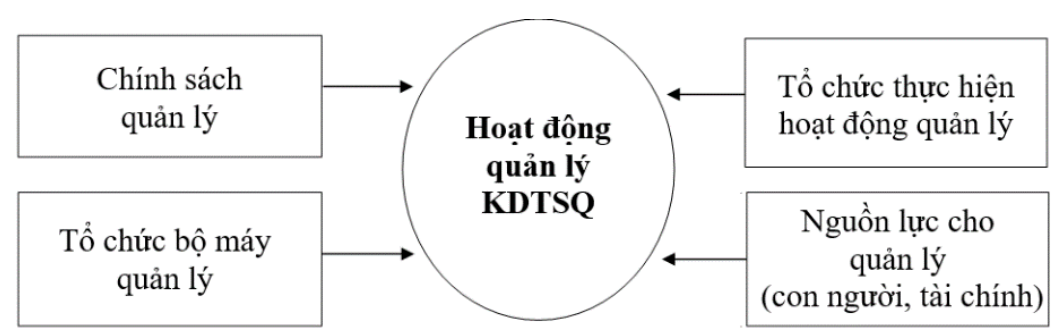

Hình 3. Khung tiếp cận nghiên cứu.

\section{Kết quả và thảo luận}

Qua phân tích 4 yếu tố của khung tiếp cận kể trên, nghiên cứu này đã có một số phát hiện cụ thể như sau:

\subsection{Về chính sách quản lý khu dụ trũ sinh quyển}

Hiện tại đã có các chính sách tương đối chặt chẽ liền quan đến quản lý ở vùng lõi của các KDTSQ, gồm vườn quốc gia (VQG), khu bảo tồn thiên nhiên (KBTTN) và khu bảo vệ cảnh quan (KBVCQ). Thậm chí, một số chính sách có tính đột phá, mở đường cho việc huy động, xã hội hóa các nguồn đầu tư, từng bước tạo lập tài chính bền vững cho hoạt động của các khu vực này. Tuy nhiên, một thách thức đặt ra là hiện nay KDTSQ không được đề cập đến trong hệ thống chính sách quốc gia như là một thể thống nhất. Cụ thể, khái niệm KDTSQ vẫn chưa có trong hệ thống quy phạm pháp luật quản lý quốc gia hiện hành và thiếu một khung pháp lý chuyên biệt dành cho việc quản lý các KDTSQ. Hiện tại, Luật tổ chức Hội đồng nhân dân và Ưy ban nhân dân (2003) vẫn chưa đề cập đến chức năng quản lý nhà nước về quản lý KDTSQ. Ngoài ra, vẫn chưa có chính sách quản lý thống nhất đối với KDTSQ từ cấp trung ương đến địa phương.

Kết quả rà soát và tham vấn chuyên gia cũng cho thấy, các hướng dẫn về các quy định chung đối với quản lý KDTSQ vẫn còn đang rất thiếu. Mặc dù KDTSQ được đề cập đến trong Chiến lược quốc gia về đa dạng sinh học đến năm 2020,

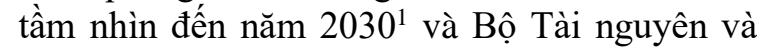

\footnotetext{
${ }^{1}$ Quyết định số 1250/QĐ-TTg của Thủ tướng Chính phủ ngày 31 tháng 07 năm 2013 về phê duyệt Chiến lược quốc gia về đa dạng sinh học đến năm 2020, tầm nhìn đến năm 2030.
}

Môi trường (TN\&MT) được giao nhiệm vụ làm đầu mối quốc gia, nhằm chỉ đạo, hướng dẫn việc lập hồ sơ đề cử công nhận và quản lý các $\mathrm{KDTSQ}^{2}$, tuy nhiên cho đến nay, Bộ vẫn chưa ban hành được bất cứ một văn bản quy phạm pháp luật nào về KDTSQ. Đặc biệt là các chính sách liên quan tới việc tổ chức quản lý thống nhất các KDTSQ, cũng như định hướng cho sự phát triển của hệ thống này trong tương lai.

3.2. Về co cấu và chức năng của các co quan quản lý khu dụ trũ sinh quyển

Tại Việt Nam, KDTSQ chịu sự quản lý của nhiều cơ quan khác nhau. Trong khi vùng lõi (VQG/KBTTN/KBVCQ) được quản lý trực tiếp theo ngành dọc của các bộ chuyên ngành (Bộ NN\&PTNT, Bộ TN\&MT), thì vùng đệm và vùng chuyển tiếp lại chịu sự quản lý của các địa phương. Do đó, để tổ chức phối hợp hoạt động của các sở, ban, ngành liên quan, của các cấp chính quyền địa phương và cộng đồng, các KDTSQ đã thành lập các Ban quản lý $(B Q L)$ và các bộ phận hỗ trợ (gọi chung là $\mathrm{BQL}$ ). Đối với các KDTSQ nằm trong ranh giới 1 tỉnh, quyết định thành lập $\mathrm{BQL}$ do UBND tỉnh phê duyệt. Trong trường hợp KDTSQ nằm trong ranh giới của nhiều tỉnh như KDTSQ Châu thổ sông Hồng, quyết định thành lập $\mathrm{BQL}$ do Ủy ban quốc gia UNESCO Việt Nam ban hành. BQL thực hiện nhiệm vụ tham mưu giúp UBND tỉnh/thành phố quản lý KDTSQ theo các quy định của pháp luật Việt Nam và theo hướng dẫn về chuyên môn, nghiệp vụ của Ủy ban quốc gia UNESCO Việt

\footnotetext{
${ }^{2}$ Nghị định số 36/2017/NĐ-CP của Thủ tướng Chính phủ ngày 04/4/2017 về việc quy định chức năng, nhiệm vụ, quyền hạn và cơ cấu tổ chức của Bộ TN\&MT
} 
Nam và Ủy ban Quốc gia Chương trình Con người và Sinh quyển (MAB Việt Nam).

- Về cơ cấu tổ chức, các BQL KDTSQ hiện chưa có mô hình tổ chức thống nhất. Mỗi địa phương hình thành bộ máy tổ chức quản lý KDTSQ tùy thuộc tiếp cận của mình. Các KDTSQ thường có một cơ cấu sau: (1) Ban quản lý; (2) Văn phòng hoặc Bộ phận thư ký; (3) Hội đồng tư vấn. Cụ thể: BQL do một lãnh đạo cấp tỉnh/thành phố làm trưởng ban, với các thành viên là lãnh đạo các sở, ban, ngành, UBND các huyện thuộc KDTSQ. Tùy theo điều kiện đặc thù của từng KDTSQ, một số thành viên $\mathrm{BQL}$ là đại diện của các bên có liên quan khác tại địa phương cũng tham gia như: các nhà khoa học, tổ chức chính trị xã hội. Tuy nhiên, hầu hết thành viên BQL các KDTSQ vẫn chủ yếu là các thành viên của cơ quan quản lý nhà nước, sự tham gia của cộng đồng và doanh nghiệp còn tương đối vắng bóng [13]. Đồng thời, sự phối hợp của các bên còn tương đối yếu. Ví dụ BQL KDTSQ Cù Lao Chàm đã có đại diện đầy đủ 4 thành phần (nhà quản lý - nhà khoa học - nhà doanh nghiệp - cộng đồng), tuy nhiên, sự tham gia của đại diện 4 nhà chưa thật sự đồng đều, sự phối hợp còn hạn chế [14]. Ngoài ra, một đặc thù của BQL KDTSQ là hầu hết các thành viên đều làm việc theo chế độ kiêm nhiệm.

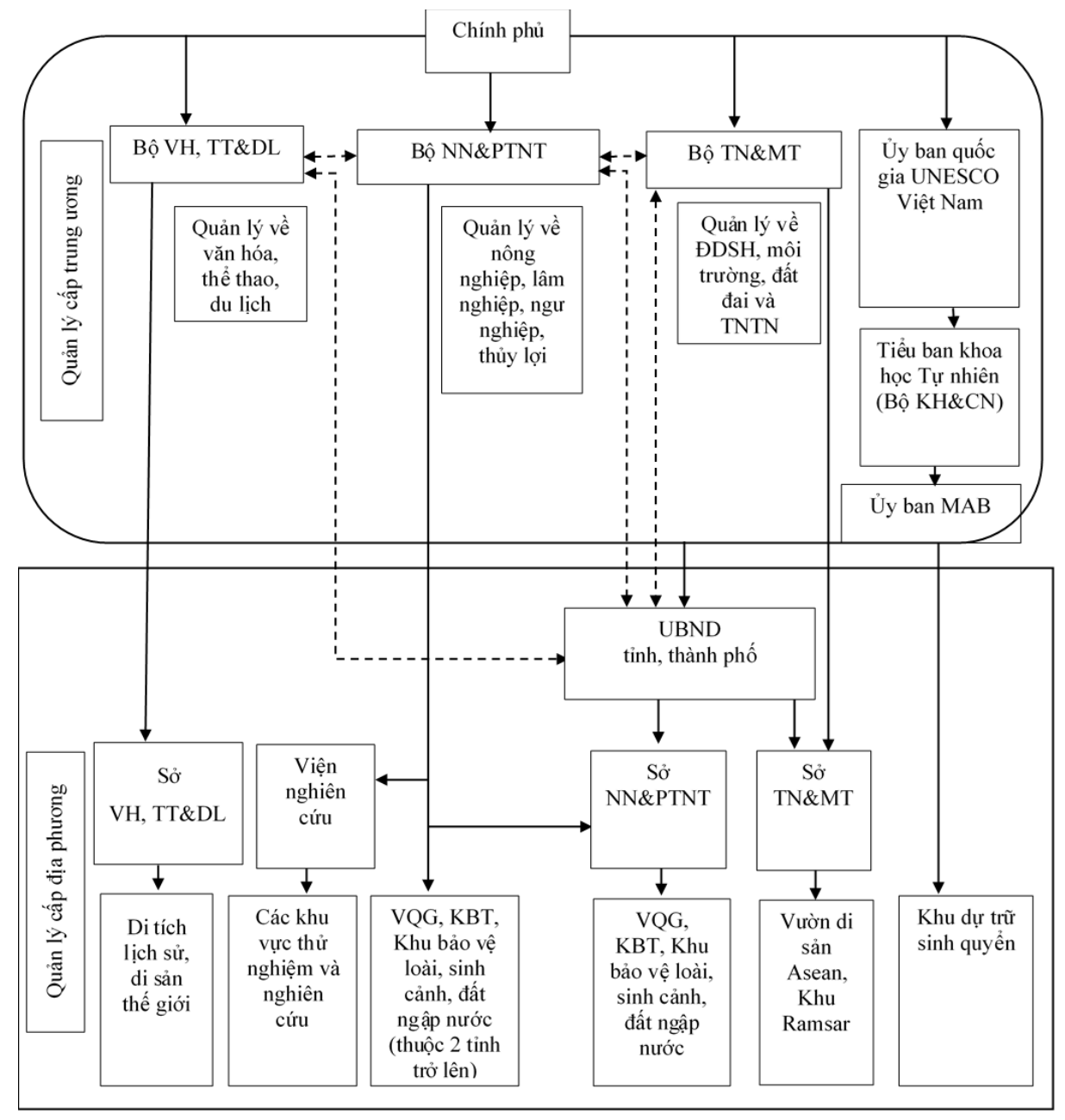

Hình 4. Hệ thống quản lý KDTSQ tại Việt Nam.

Nguồn: Van Cuong et al., (2017) [8] 
- Về chưc năng, BQL thường không quản lý trực tiếp về mặt lãnh thổ mà tồ chức điều phối các hoạt động. Hiện tại, việc quản lý các KDTSQ dựa trên sự hợp tác giữa $\mathrm{MAB}$ Việt $\mathrm{Nam}$ và $\mathrm{BQL}$ của các KDTSQ.

Tính đến thời điểm hiện tại, MAB Việt Nam cũng chưa đưa ra được một hướng dẫn mang tính thống nhất để giúp các KDTSQ kiện toàn bộ máy tổ chức và quy chế thực hiện. Theo ý kiến tham vấn chuyên gia, điều này dẫn tới nhiều KDTSQ hiện vẫn gặp khó khăn trong việc kiện toàn bộ máy tổ chức quản lý. Điển hình như KDTSQ miền Tây Nghệ An, phải sau 6 năm thành lập mới thành lập được BQL KDTSQ và sau 7 năm mới ban hành được quy chế quản lý. KDTSQ Mũi Cà Mau, sau 5 năm thành lập, quy chế quản lý mới được ban hành.

Bên cạnh đó, các chuyên gia cũng cho rằng, nhiều khu KDTSQ ở Việt Nam nằm trong nhiều huyện của 1 tỉnh, hoặc nhiều tỉnh với diện tích và dân số rất lớn, nên công tác quản lý của KDTSQ đặt ra nhiều vấn đề cần phải giải quyết. Điển hình như KDTSQ Đồng Nai, nằm trong địa giới hành chính của 5 tỉnh, 18 huyện, 1 thành phố và 1 thị xã. Tuy nhiên, $B Q L$ chỉ bao gồm các thành phần nhà nước, đại diện tổ chức xã hội và doanh nghiệp của tỉnh Đồng Nai, nên những hoạt động của KDTSQ tại 4 tỉnh còn lại không mạnh mẽ, thậm chí không có hoạt động nào được thực hiện dưới danh nghĩa của KDTSQ như một thể thống nhất.

\subsection{Về tổ chức thực hiện quản lý của các khu dụ trũ sinh quyển tại Việt Nam}

Nguyên tắc thứ 2 trong 4 nguyên tắc quản lý KDTSQ trong Khung Pháp lý của Mạng lưới toàn cầu các KDTSQ thế giới đã nhấn mạnh tầm quan trọng của việc xây dựng được một chiến lược/kế hoạch trong quản lý KDTSQ [2]. Bởi lẽ đây là cơ sở quan trọng để quản lý các KDTSQ một cách thống nhất, xuyên suốt, có định hướng và là căn cứ quan trọng để $\mathrm{BQL}$ KDTSQ huy động được những nguồn lực cần thiết để triển khai thực hiện những hoạt động của mình.

Về công tác xây dựng và thực hiện kế hoạch của các khu dư trũ sinh quyển tại Việt Nam
Hiện tại, do thiếu hụt các hướng dẫn về quản lý KDTSQ, nên các chính sách phát triển dài hạn đều là các sáng kiến của BQL KDTSQ. KDTSQ Đồng Nai đã xây dựng đề án bảo tồn và phát triển KDTSQ giai đoạn 2015-2020 và tầm nhìn đến 2030; KDTSQ miền Tây Nghệ An đã xây dựng định hướng chiến lược quản lý bền vững KDTSQ giai đoạn 2017-2027; KDTSQ Kiên Giang đã xây dựng kế hoạch hành động 20132015, tầm nhìn 2020; KDTSQ Cù Lao ChàmHội An đã xây dựng kế hoạch quản lý tổng hợp 2015-2019, tầm nhìn 2030; KDTSQ Cần Giờ đã xây dựng dự án tổ chức quản lý bền vững tầm nhìn 2025; KDTSQ Langbiang đã xây dựng và đưa vào thực hiện kế hoạch quản lý 05 năm (2018-2022); KDTSQ quần đảo Cát Bà là KDTSQ đầu tiên tại Việt Nam đã xây dựng Kế hoạch hành động Lima cho KDTSQ của mình. Trong khi đó, KDTSQ Châu thổ sông Hồng và Mũi Cà Mau vẫn đang loay hoay trong việc kiện toàn bộ máy quản lý và vẫn chưa xây dựng được kế hoạch phát triển dài hạn. Theo kết quả tham vấn chuyên gia, mặc dù một số KDTSQ đã xây dựng được các kế hoạch quản lý dài hạn, một số kết hoạch vẫn còn nhiều điểm chưa tương thích với hệ thống giám sát theo Khung Pháp lý và Kế hoạch hành động Lima. Kết quả này cũng tương đồng phát hiện trong nghiên cứu của Van Cuong và cộng sự (2018) tại KDTSQ Kiên Giang [13].

Hiện trạng thực tế và kết quả tham vấn ý kiến chuyên gia cũng cho thấy, nỗ lực quản lý ở hầu hết các KDTSQ thường tập trung vào bảo tồn đa dạng sinh học truyền thống trong vùng lõi - khu vực bảo vệ nghiêm ngặt. Trong khi đó, rất ít chú ý tới vùng đệm và vùng chuyển tiếp cũng như toàn bộ KDTSQ như một chỉnh thể thống nhất. Các mục tiêu lớn hơn về phát triển bền vững và lợi ích kinh tế từ KDTSQ vẫn chưa được thực hiện đầy đủ hoặc chỉ được thực hiện thông qua một số các dự án hạn chế. Điển hình như KDTSQ Châu thổ sông Hồng, ngoài các hoạt động chuyên môn của 2 vùng lõi chính là VQG Xuân Thủy và KBTTN đất ngập nước Tiền Hải cùng các $\mathrm{Chi}$ cục Biển, đảo là đầu mối của KDTSQ trực thuộc Sở TN\&MT 3 tỉnh, trong năm 2019, KDTSQ không có hoạt động nổi bật nào do không có nguồn lực chủ đạo. Hay 
KDTSQ Mũi Cà Mau, hoạt động năm 2019 mới chỉ dừng lại ở một vài hoạt động truyền thông là chủ yếu [15]. Những mô hình nâng cao thu nhập người dân theo hướng gắn với bảo tồn thiên nhiên còn ít và chưa thực sự đạt hiệu quả cao, bền vững, chưa xứng tầm với vị trí đáng có trong chuỗi giá trị quốc gia, khu vực và toàn cầu [16]. BQL KDTSQ cũng chưa chủ động thực hiện các chương trình dự án, chỉ tham gia mang tính phối hợp nên hiệu quả mang lại chưa cao [17].

\section{Về quy trình quản lý và điều phối}

Đảm bảo sự tham gia và hợp tác của các bên liên quan được xem là 2 nhân tô quan trọng nhất ảnh hưởng đến sự thành công trong quản lý KDTSQ $[8,13,18]$. Do có rất nhiều bên liên quan trong KDTSQ (Hình 5), việc quản lý một KDTSQ thực chất là công việc điều phối sự hợp tác và tham gia của các bên tuân theo các định chế pháp lý hiện hành, dựa trên nguyên tắc đồng thuận, chia sẻ lợi ích và trách nhiệm [5].

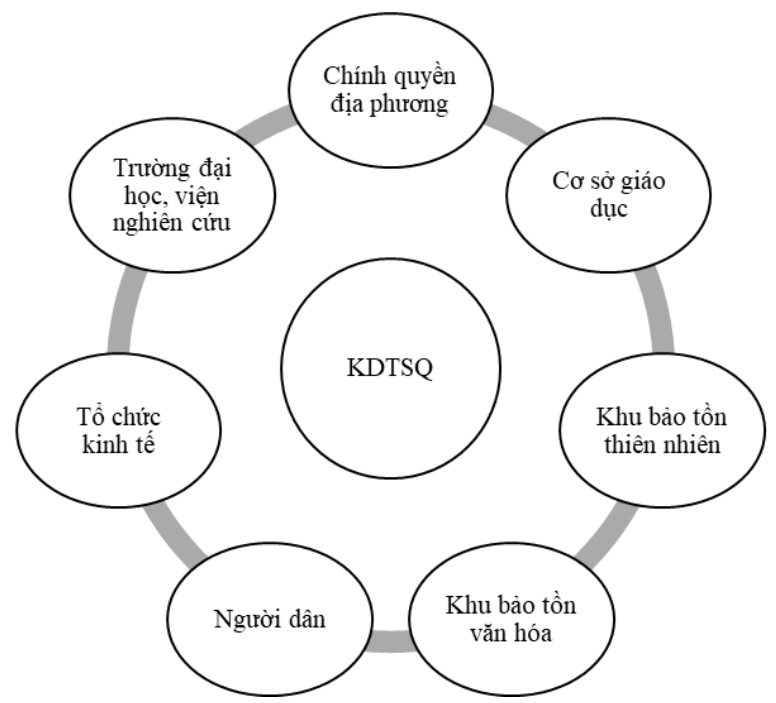

Hình 5. Các bên liên quan trong KDTSQ.

Nguồn: Tri et al., (2014) [5]

Hiện tại, 8/9 KDTSQ chưa xây dựng và ban hành được cơ chế điều phối, hợp tác và chia sẻ thông tin giữa các bên liên quan. Kết quả tham vấn chuyên gia của nghiên cứu này cũng cho thấy, mặc dù KDTSQ Châu thổ sông Hồng đã ban hành quy chế phối hợp liên tỉnh ${ }^{3}$, tuy nhiên, các hoạt động hợp tác liên vùng giữa các tỉnh trong KDTSQ còn hạn chế.

Theo chức năng nhiệm vụ, BQL KDTSQ đóng vai trò chủ đạo trong việc thúc đẩy sự tham gia và hợp tác của các bên liên quan. Hiện tại, $\mathrm{BQL}$ do phó chủ tịch tỉnh/thành phố làm chủ tịch. Điều này đã tạo điều kiện thuận lợi cho việc huy động các nguồn lực và điều phối các bền

\footnotetext{
${ }^{3}$ Quyết định số 466/QĐ-UBQG UNESCO ngày 26/7/2013 ban hành quy chế phối hợp quản lý bảo tồn và phát triển bền
}

tham gia. Tuy nhiên, sự phối hợp và quản lý thực tế của KDTSQ thường thuộc về một sở hoặc VQG/KBTTN nằm dưới sự quản lý của Chi cục Lâm nghiệp thuộc Sở NN\&PTNT. Sự phối hợp liên ngành trong thực hiện quản KDTSQ còn hạn chế [8]. Ví dụ, cơ chế đồng quản lý và chia sẻ lợi ích giữa $B Q L K D T S Q$ và cộng đồng thông qua đồng quản lý và chia sẻ lợi ích ở KDTSQ Cù Lao Chàm - Hội An và Châu thổ sông Hồng được thực hiện giữa VQG và cộng đồng địa phương dưới sự hỗ trợ từ các dự án thay vì BQL KDTSQ [19].

Mặc dù sự tham gia và hợp tác mạnh mẽ giữa khu vực công lập và ngoài công lập là một trong

vững khu DTSQ đất ngập nước liên tỉnh ven biển đồng bằng Châu thổ sông Hồng. 
những nhân tố quan trọng để đảm bảo thành công trong quản lý KDTSQ [20,21], tuy nhiên kết quả tham vấn chuyên gia cho thấy, các quyết định lập kế hoạch và quản lý cho KDTSQ cho đến nay chỉ có sự tham gia của cơ quan cấp tỉnh và các sở chuyên ngành, trong khi sự tham gia của cộng đồng địa phương và khu vực tư nhân còn rất hạn chế. Gần đây, sự tham gia của cộng đồng trong công tác quản lý KDTSQ cũng bắt đầu được chú trọng, điều này thể hiện ở sự phối hợp giữa các cơ quan nhà nước với cộng đồng dân cư trong việc xây dựng một số quy hoạch, kế hoạch, chương trình quản lý và phát triển sinh kế thuộc KDTSQ [22].

\subsection{Về nguồn lực cho quản lý}

Trước hết, về nguồn nhân lực quản lý. Số cán bộ trực tiếp làm việc liên quan đến công tác quản lý của các KDTSQ khoảng 30 người (1 trưởng ban, 2-6 phó trưởng ban, 18-21 ủy viên, 4-6 thành viên ban thư ký/văn phòng). Tuy nhiên, điểm đặc thù của các KDTSQ là các thành viên của $\mathrm{BQL}$ thường là lãnh đạo của các sở, ban, ngành, UBND địa phương (cấp huyện) và các VQG/KBTTN/KBVSC trong phạm vi không gian của KDTSQ và làm việc với cơ chế kiêm nhiệm là chủ yếu. Mỗi đơn vị, cơ quan này lại có một bộ máy với các nguồn lực riêng biệt để thực hiện các chứ năng nhiệm vụ của mình. Ví dụ, BQL KDTSQ Kiên Giang hoạt động theo hình thức kiêm nhiệm gồm 01 trưởng ban là Phó Chủ tịch UBND tỉnh Kiên Giang, 6 Phó Trưởng ban (Giám đốc Sở Khoa học và Công nghệ là phó trưởng ban thường trực) và 21 ủy viên là đại diện lãnh đạo các sở ngành, địa phương. Hay đối với KDTSQ Châu thổ sông Hồng, Trưởng ban là Phó Chủ tịch UBND tỉnh phụ trách TN\&MT của một trong 3 tỉnh được bầu theo cơ chế luân phiên 5 năm/1 nhiệm kỳ, 2 Phó Trưởng ban là 2 Phó Chủ tịch UBND phụ trách TN\&MT của hai tỉnh còn lại. Như vậy, công tác quản lý hay hiệu quả quản lý của KDTSQ, về thực chất là công việc và mức độ huy động, điều phối được nguồn nhân lực sẵn có từ các cơ quan, đơn vị mà lãnh đạo là thành viên của $B Q L$ KDTSQ.

Kết quả thực tế và tham vấn ý kiến chuyên gia cũng cho thấy, sự kiêm nhiệm của các thành viên ở tất cả các BQL KDTSQ là một vấn đề cần được xem xét. Họ đều là lãnh đạo các cơ quan quản lý của địa phương hay tổ chức xã hội. Công việc chính của họ cũng khá nặng nề, cả về khối lượng công việc cần giải quyết hàng ngày, cũng như thời gian dành cho giải quyết các công việc đó. Điều này dẫn tới việc dành thời gian của họ cho các hoạt động liên quan đến KDTSQ còn hạn chế. Đây cũng là một trong những khó khăn trong công tác quản lý KDTSQ. Bên cạnh đó, hầu hết các thành viên $B Q L$ và nhân viên chỉ được đào tạo đơn ngành, hiểu biết của họ về vai trò của việc quản lý và lập kế hoạch quản lý KDTSQ như là một quá trình tích hợp còn giới hạn $[13,23]$. Khả năng ngoại ngữ chưa đáp ứng yêu cầu hợp tác quốc tế, nghiên cứu khoa học [24]. Đồng thời, nguồn kinh phí phục vụ cho việc nâng cao năng lực, đặc biệt là năng lực quản lý và yêu cầu kiến thức hệ thống cho đổi mới, thay đổi còn hạn chế [19].

Thứ hai, về nguồn lực tài chính cho quản lý. Các nguồn tài chính cơ bản cho hoạt động quản lý của KDTSQ bao gồm: (1) nguồn ngân sách của nhà nước; (2) nguồn ngân sách cho vùng lõi của KDTSQ; (3) nguồn kinh phí từ các đề tài dự án hợp tác; (4) nguồn kinh phí từ hoạt động du lịch, chi trả dịch vụ môi trường rừng; (5) nguồn kinh phí khác (các nguồn kinh phí tự chủ, bao gồm các hoạt động nghiên cứu, dịch vụ và phát triển).

Do KDTSQ hiện nay về thực chất vẫn chưa phải thực thể quản lý đầy đủ và đúng nghĩa đặt ra một thách thức cho các KDTSQ để có được ngân sách của trung ương. Hiện tại, hoạt động của các KDTSQ hiện vẫn phụ thuộc vào ngân sách tỉnh và các dự án bên ngoài.

Nhìn chung, nguồn lực tài chính cho quản lý các KDTSQ còn vừa rất hạn chế so với nhu cầu quản lý (khoảng 1 tỷ đồng/năm/KDTSQ cho hoạt động điều phối của BQL KDTSQ), tương đối ít kết nối với hệ thống quản lý tài chính công ở địa phương. Nguồn tài chính này hiện chủ yếu dựa vào nguồn ngân sách nhà nước, cấp vào tài khoản của một sở đầu mối (thường là Sở NN\&PTNT) theo dự trù hàng năm, được UBND cấp tỉnh/thành phố phê duyệt. Việc phân bổ kinh phí phụ thuộc rất nhiều vào các điều kiện kinh tế 
cụ thể của mỗi địa phương. Chẳng hạn, KDTSQ Cần Giờ, Cát Bà và Đồng Nai có được sự hỗ trợ tài chính tốt hơn so với các KDTSQ khác như Châu thổ sông Hồng, Tây Nghệ An vì cả Đồng Nai, Quảng Ninh và Thành phố Hồ Chí Minh đều là những tỉnh có nguồn thu ngân sách lớn. Với số kinh phí này, các BQL KDTSQ chủ yếu thực hiện các hoạt động chi thường xuyên và một vài hoạt động đào tạo cán bộ và nâng cao nhận thức cho cộng đồng. Trừ vùng lõi của KDTSQ được quy định nguồn tài chính theo luật định, vùng đệm và vùng chuyển tiếp của KDTSQ nằm trên địa bàn quản lý của một hay một vài huyện, xã, nhưng hiện không có quy định nào về tài chính (cấp tỉnh, thành phố, huyện, xã) dành cho quản lý vùng đệm và vùng chuyển tiếp của KDTSQ.

Các dự án bên ngoài là nguồn tài trợ lớn thứ hai (sau ngân sách chính phủ) cho đa dạng sinh học và bảo vệ môi trường tại Việt Nam [22]. Bên cạnh đó, phần lớn các chuyên gia được tham vấn trong nghiên cứu này cũng cho rằng, việc huy động nguồn ngoài ngân sách nhà nước là rất khó khăn, ít ỏi và chưa ổn định (thường là một số đóng góp mang tính tài trợ của một số tổ chức quốc tế, doanh nghiệp). Ngoài ra, hoạt động tài trợ thường tập trung vào "điều trị triệu chứng" thay vì can thiệp ở quy mô hệ thống [25]. Một số dự án quy mô nhỏ, thời gian thực hiện ngắn, các hoạt động được thiết kế riêng rẽ, thiếu liên kết đồng bộ với các hoạt động của các chương trình/dự án khác [13]. Điều này dẫn đến các can thiệp có thể có tác động tạm thời nhưng chưa thiết lập các giải pháp lâu dài và bền vững.

Thực tế hiện nay, chưa có cơ chế huy động nguồn lực tài chính mang tính chất bền vững từ các hoạt động phát triển (du lịch, nuôi trồng thủy hải sản, nghiên cứu khoa học ...). Ngoài KDTSQ quần đảo Cát Bà đã thiết lập Quỹ phát triển bền vững ${ }^{4}$, hiện tại, quan hệ đối tác giữa KDTSQ với các bên liên quan để tạo nguồn lực quản lý còn hạn chế.

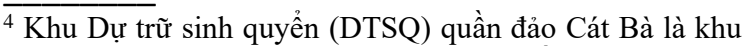
DTSQ đầu tiên trong khu vực Đông Nam Á thành lập Quỹ Phát triển bền vững Khu DTSQ. Đây là Khu SQTG đầu tiên
}

\section{Kết luận}

Việt Nam bắt đầu tham gia mạng lưới các KDTSQ thế giới từ năm 2000. Cho đến nay, Việt Nam đứng thứ 2 tại khu vực Đông Nam Á về số lượng KDTSQ. Đây là những khu vực chứa HST đa dạng, văn hóa và kinh tế tiêu biểu, đóng góp quan trọng trong việc bảo tồn, phát triển bền vững của khu vực và quốc gia. Tuy nhiên, thực tế cho thấy, vẫn còn nhiều thách thức trong quản lý các KDTSQ hiện nay.

Thú nhất, KDTSQ vẫn chưa được đưa vào hệ thống luật pháp quốc gia như một thể thống nhất. Điều này dẫn đến việc thiếu khung pháp lý liên quan đến quản lý, giám sát các KDTSQ.

Thư hai, cơ cấu quản lý KDTSQ ở Việt Nam chưa thống nhất và không được phân định đầy đủ ở cả cấp quốc gia và cấp địa phương. Sự vắng mặt của cộng đồng, các tổ chức xã hội và khu vực tư nhân trong hệ thống quản lý các KDTSQ là một trong những thách thức trong việc quản lý, thiết lập quan hệ đối tác công - tư có sự tham gia của cộng đồng trong quản lý KDTSQ.

Thú $b a$, sự phối hợp liên ngành trong công tác lập kế hoạch và quản lý KDTSQ ở Việt Nam đặc biệt bị giới hạn bởi địa giới hành chính. Do thiếu các hướng dẫn về quản lý KDTSQ, nên các kế hoạch quản lý hiện nay đều là các sáng kiến của địa phương. Các kế hoạch quản lý dài hạn các KDTSQ ở Việt Nam vẫn chưa thực sự tương thích theo Khung Pháp lý và Kế hoạch hành động Lima. Đồng thời, sự tham gia của cộng đồng địa phương và khu vực tư nhân vào việc lập kế hoạch và quản lý còn hạn chế. Các mục tiêu lớn hơn về phát triển bền vững và lợi ích kinh tế từ KDTSQ vẫn chưa được thực hiện đầy đủ hoặc chỉ được thực hiện thông qua một số các dự án.

Thư $t u$, việc xây dựng và thực hiện cơ chế điều phối, hợp tác và chia sẻ thông tin giữa các bên liên quan tại các KDTSQ còn thiếu và thực hiện chưa hiệu quả. Các hoạt động hợp tác liên vùng giữa các tỉnh trong KDTSQ còn hạn chế. Các BQL KDTSQ chưa thực sự phát huy một

triển khai doanh nghiệp xã hội, là thành viên của mạng lưới vốn xã hội và doanh nghiệp xã hội trong các khu SQTG toàn cầu. 
cách tích cực trong việc điều phối sự tham gia của các bên liên quan.

Thư năm, nguồn nhân lực cho hoạt động quản lý KDTSQ còn hạn chế. Việc cán bộ quản lý chủ yếu là kiêm nhiệm và thiếu những kỹ năng và kinh nghiệm cần thiết, nên đây cũng là những khó khăn trở ngại lớn của các KDTSQ.

Thư sáu, thiếu khung pháp lý quốc gia liên quan tạo ra khó khăn cho các KDTSQ có được tài trợ từ ngân sách trung ương. Hoạt động của các KDTSQ chỉ dựa vào nguồn phân bổ hạn chế từ tỉnh/thành phố trực thuộc và sự hỗ trợ không thường xuyên của các tổ chức quốc tế. Việc thiếu kinh phí hoạt động khiến các KDTSQ hoạt động chưa thực sự hiệu quả. Hiện tại, chưa có cơ chế huy động nguồn lực tài chính mang tính chất bền vững từ các hoạt động phát triển. Quan hệ đối tác giữa KDTSQ với các bên liên quan để tạo nguồn lực quản lý còn hạn chế.

\section{Tài liệu tham khảo}

[1] N. Ishwaran, A. Persic, N. H. Tri, Concept and Practice: The Case of UNESCO Biosphere Reserves, International Journal of Environment and Sustainable Development, Vol. 7, No. 2, 2008, pp. 118-131,

https://doi.org/10.1504/IJESD.2008.018358.

[2] UNESCO, Biosphere Reserves: the Seville Strategy and the Statutory Framework of the World Network, 1996,

https://unesdoc.unesco.org/ark:/48223/pf0000103 849.

[3] UNESCO, Lima Action Plan for UNESCO's Man and the Biosphere (MAB) Programme and its World Network of Biosphere Reserves (20162025) as endorsed by the 4th World Congress of Biosphere Reserves on 17 March 2016, and as adopted by the 28th MAB ICC on 19 March 2016, Lima, Peru, 2016,

http://www.unesco.org/new/fileadmin/MULTIME DIA/HQ/SC/pdf/Lima_Action_Plan_en_final.pdf.

[4] UNESCO, World Network of Biosphere Reserves, 2020 , https://en.unesco.org/biosphere/wnbr (accessed on: June 18th, 2020).

[5] N. H. Tri, T. T. Hoa, L. T. Tuyen, Management of MAB Vietnam's Network of Biosphere Reserves Through the Approach of System Thinking,
Land/seascape Planning, Inter-sectoral Coordination and Quality Economy (SLIQ), the 57th Annual Meeting of the ISSS, Hai Phong, Vietnam, 2014,

https://journals.isss.org/index.php/proceedings57t $\mathrm{h} /$ article/view/2118.

[6] UNESCO, The MAB Strategy 2015-2025, 2015, http://www.unesco.org/new/fileadmin/MULTIME DIA/HQ/SC/pdf/MAB_Strategy_20152025_final_text.pdf.

[7] K. L. Coetzer, E. T. Witkowski, B. F. Erasmus, Reviewing Biosphere Reserves Globally: Effective Conservation Action or Bureaucratic Label?, Biological Reviews, Vol. 89, No. 1, 2014, pp. 82104, https://doi.org/10.1111/brv.12044.

[8] C. Van Cuong, P. Dart, N. Dudley, M. Hockings, Factors Influencing Successful Implementation of Biosphere Reserves in Vietnam: Challenges, opportunities and Lessons Learnt, Environmental Science and Policy, Vol. 67, 2017, pp. 16-26, https://doi.org/10.1016/j.envsci.2016.10.002.

[9] UNESCO, Directory of the World Network of Biosphere Reserves (WNBR), 2020,

http://www.unesco.org/new/en/naturalsciences/environment/ecologicalsciences/biosphere-reserves/world-networkwnbr/wnbr/ (accessed on: June 5th, 2020)

[10] UNESCO MAB, MAB Vietnam, UNESCO Vietnam, Handbook of frequently asked questions about Biosphere Reserves in Vietnam, Hanoi, Vietnam, 2021 (in Vietnamese)

[11] German MAB National Committee, Criteria for Designation and Evaluation of UNESCO Biosphere Reserves in Germany, 1996, https://www.bfn.de/fileadmin/BfN/gebietsschutz/ Dokumente/BR_Kriterien_nat_eng.pdf (accessed on: June 18th, 2020).

[12] R. Pool-Stanvliet, S. Stoll-Kleemann, J. H. Giliomee, Criteria for Selection and Evaluation of Biosphere Reserves in Support of the UNESCO MAB Programme in South Africa, Land Use Policy, Vol. 76, 2018, pp. 654-663, https://doi.org/10.1016/j.landusepol.2018.02.047.

[13] C. V. Cuong, P. Dart, N. Dudley, M. Hockings, Building Stakeholder Awareness and Engagement Strategy to Enhance Biosphere Reserve Performance and Sustainability: The Case of Kien Giang, Vietnam, Environmental Management, Vol. 62, No. 5, 2018, pp. 877-891, https://doi.org/10.1007/s00267-018-1094-6. 
[14] Management Board of $\mathrm{Cu}$ Lao Cham-Hoi An Biosphere Reserve, Performance Report in 2019 and Orientation for 2020, 2019 (in Vietnamese)

[15] N. H. Tri , V. T. Hien, Implementation of the Lima Action Plan "Promoting Eco-tourism in the World's Biosphere Reserves in Vietnam", Performance Review Workshop in 2019, Orientation for 2020, Hoi An, Vietnam, 2019, (in Vietnamese).

[16] Management Board of Cat $\mathrm{Ba}$ Archipelago Biosphere Reserve, Performance Report in 2019 and Orientation for 2020, 2019 (in Vietnamese).

[17] Management Board of Mui Ca Mau Biosphere Reserve, Performance Report in 2019 and Orientation for 2020, 2019 (in Vietnamese).

[18] C. V. Cuong, P. Dart, M. Hockings, Biosphere Reserves: Attributes for Success, Journal of Environmental Management, Vol. 188, 2017, pp. 9-17, https://doi.org/10.1016/j.jenvman.2016.11.069.

[19] C. Van Cuong, P. Dart, N. M. Ha, V. T. M. Le, M. Hockings, Biosphere Reserves in Vietnam: Management Challenges, in: M. G. Reed and M. F. Price (Eds.), UNESCO Biosphere Reserves: Supporting Biocultural Diversity, Sustainability and Society, Routledge, London, 2019, pp. 201212 , https://doi.org/10.4324/9780429428746.

[20] S. Stoll-Kleemann, A. C. de la Vega-Leinert, L. Schultz, The Role of Community Participation in the Effectiveness of UNESCO Biosphere Reserve
Management: Evidence and Reflections from Two Parallel Global Surveys, Environmental Conservation, Vol. 37, No. 3, 2010, pp. 227-238, https://doi.org/10.1017/S037689291000038X.

[21] S. Stoll-Kleemann, M. Welp, Society, Participatory and Integrated Management of Biosphere Reserves Lessons from Case Studies and a Global Survey, Gaia-ecological Perspectives for Science, Vol. 17, 2008, pp. 161-168, https://doi.org/10.14512/gaia.17.S1.14.

[22] V. T. Son, Final Report on Implementation of National Science and Technology Task: Research and Development of a Set of Criteria and Process for Monitoring and Evaluation of the Efficiency of Management of Biosphere Reserves in Vietnam. Institute of Natural Resources and Environment, Hanoi National University, 2018 (in Vietnamese).

[23] Management Board of Hong River Delta Biosphere Reserve, Performance Report in 2019 and Orientation for 2020, 2019 (in Vietnamese).

[24] D. H. Giap, N. H. Tri, H. T. N. Ha, 10 Year Reriodic Review Report of Western Nghe An Biosphere Reserve. Report submitted to UNESCO, 2017.

[25] N. C. Nguyen, O. J. Bosch, A Systems Thinking Approach to identify Leverage Points for Sustainability: A Case Study in the Cat Ba Biosphere Reserve, Vietnam, Systems Research and Behavioral Science, Vol. 30, No. 2, 2013, pp. 104-115, https://doi.org/10.1002/sres.2145. 